\title{
The Effectiveness of Life Skills Training on Enhancing the Self-Esteem of Hearing Impaired Students in Inclusive Schools
}

\author{
Abbas Mahvashe Vernosfaderani \\ Department of Psychology, Social Welfare \& Rehabilitation Sciences University, and Special Education, \\ Ministry of Education of Arak Province, Arak, Iran \\ Email: abasmahvash@yahoo.com
}

Received October 13, 2013; revised November 13, 2013; accepted November 20, 2013

Copyright (c) 2014 Abbas Mahvashe Vernosfaderani. This is an open access article distributed under the Creative Commons Attribution License, which permits unrestricted use, distribution, and reproduction in any medium, provided the original work is properly cited. In accordance of the Creative Commons Attribution License all Copyrights (C) 2014 are reserved for SCIRP and the owner of the intellectual property Abbas Mahvashe Vernosfaderani. All Copyright (c) 2014 are guarded by law and by SCIRP as a guardian.

\section{ABSTRACT}

This research investigates the effectiveness of life skills training on enhancing the self-esteem of 8 - 16 years-old students with hearing impairment in inclusive schools. The sample was included of 54 students with hearing impairment from inclusive school whom their age and IQ were matched. They were randomly divided into an experimental and a control group (27 students in each group). The participants were assessed by Coopersmith Self-esteem Inventory (58-items version). The gathered data were analysed using the t-test method through the SPSS package. The results showed that training life skills to students with hearing impairment promote their self-esteem. In other words, life skills training is effective for enhancing the self-esteem of hearing impaired students in inclusive schools.

\section{KEYWORDS}

Hearing Impaired Students; Self-Esteem; Life Skills Training; Inclusive Schools

\section{Introduction}

Hearing impairment is one of the most common congenital and acquired diseases in children. About 1 - 3 children in 1000 are affected [1]. Most studies concentrate on speech and language development and progress in school, only few studies focus on psychosocial aspects such as the quality of life, well-being or self-esteem in hearingimpaired children [2,3]. Reduced participation of these children in social life results in low self-confidence and self-esteem and limit the quality of life [4]. Hearing damage can cause secondary problems (perceptual problem, communication problem, emotional problem, social problem...) which based on the degree of hearing impairment, the age of child at the onset and child's intellectual potential, the magnitude of problems may vary [5]. Self-esteem is among the factors that its disturbances cause negative consequences (Kreitner and Kinicki, 2007). Students as agents of community in educational settings may suffer different problems in absence of life skills and self-esteem, since self-esteem as a necessary item in psychological structure plays several roles in social-educational functioning of the individual. Children begin to learn the social skills from early stages in life. For children to attain the Self-esteem, they not only acquire important social behaviors for interacting with others, but also be able to use these skills in ways which are acceptable to others in their environment [6]. For children the social skills and Self-esteem are effective skills to participate in a game, cooperating, communicating and supporting others [7]. Having conversation, asking questions and responding to other questions are necessary skills for the play interaction [8]. Some researchers believe that communication deficits interfere with young hearing impaired children's normal play development and due to delay in this skill, these children engage in less social play than hearing children [9]. Self-esteem, individual and social skills have been introduced as factors to improve social relations [10] and life skills are 
effective as a collection of these skills. Life skills education can promote the social adjustment of the kids and adolescents [11]. World Health Organization [12] indicates life skills as "abilities for adaptive and positive behavior that enable individual deal effectively with the demand and challenges of life". The definition of life skills may differ across culture and settings, however analysis in this field suggest that these skills (decision making, problem solving, interpersonal relationship skills, communication skills...) are necessary for promotion of the health and well-being of children. Kingsnorth, Healy and Macarthur [13] were done a systematic review of life skill programs for youth with physical disabilities and stated that five of the six studies demonstrated short-term improvements in targeted life skills. They stated conclusions are limited because of different interventions, skills, disabilities, and outcome measures with respect to the effectiveness of the programs. Ahmadian and Fata [14] on their study examined the effect of life skills education on children with mild intellectual disability and indicated that the effect of Life skills education program had positive effects on Self-knowledge, interpersonal relationship, and anger-management.

Cunha, Heckman, Lochner \& Masterov [15] in their study stated that Skill formation is a life cycle process. It starts in the womb and goes on throughout life. There are many skills and abilities (inherited or acquired) which are important for individuals' success. Skill attainment in one stage of life can lead to attaining the skills in later stages. Cronin [16] defined life skills as "those skills or tasks that contribute to the successful, independent functioning of an individual in adulthood" (p. 54). These skills may be grouped into five categories (aligned with Halpern's) [17]: self-care and domestic living, recreation and leisure, communication and social skills, vocational skills, and other skills vital for community participation. The intervention literature indicates there are some effective interventions for teaching functional life skills to individual with disabilities, and that there is a link between life skills acquisition and life quality. When a person's various life skills increases, his/her independent functioning, social competence, and quality of life increases too $[18,19]$. The inclusive education movement has produced a shift toward accessing regular education environments, and strategies to facilitate social inclusion, meaningful participation, and academic learning instead. Teaching youth with disabilities the skills needed to function in and succeed beyond school, versus including these same youth in general education classrooms where the curriculum is largely focused on academics is practical [19]. Nunes, Pretzlik and Olsson [20] stated that deaf pupils may not be rejected in mainstream schools but they may feel isolated. They could have positive and negative reactions from other pupils. The likelihood of deaf pupils being chosen as a friend is smaller than that of a hearing pupil. The hearing pupils who chose to have deaf pupil as a friend indicated pro-social reasons for the friendship, rather than the typical enjoyment and intimacy reasons. Huether [21] compared pupils in integration classes with normal-hearing children in mainstream schools and with hearing-impaired children in special, nonintegration classes. Pupils in integration classes were more interested in social contacts and said that the hearing disorders played a much smaller role in their choice of friends than with pupils in special schools. Pupils in the integration classes demonstrated the same level of leisure activities with their peers as normal-hearing pupils, whereas non-integrated hearing-impaired pupils in special schools. Children in special schools were less assertive, and reached less favorable scores in making friends, anxiety and emotional mood.

It seems hearing impaired children have some problems with Self-esteem which cause them difficulties in their relationships with other pupils and people. They could learn these skills through good interventional programs. This study investigates the effectiveness of such a program (life skills training) on enhancing self-esteem of students with hearing impairment in inclusive schools.

\section{Method}

The experimental design with pre-test, post-test with control group was used in this study. The participants were 8 - 16 years-old students with hearing impairment, in inclusive schools of Arak city $(\mathrm{N}=73)$. Among them Fifty-four students who received Low scores on Cooper Smith self-esteem Inventory (58-items version) were selected as the sample. To determine their IQ, Leiter International Performance Scale was used. The participants were matched based on the age and intelligence and randomly assigned to experimental ( $n=27$ students) and control ( $n=27$ students) groups. The experimental group received life skills training two times a week and each session took two hours. Life skills training lasted in 7 weeks. Post-test for Cooper Smith self-esteem Inventory were administered immediately after intervention (Figure 1). The data were analyzed using the SPSS software version 16, and the level of significance was set at 0.05 for all tests. T-test was used to compare variables between the two groups.

\section{Instruments}

\subsection{Coppersmith Self-Esteem Inventory}

Coopersmith's Self-Esteem Inventory (1981) was used to measure students' self-esteem. Self-esteem was measured with the Persian version of the Coopersmith's SelfEsteem Inventory (SEI). The SEI form used in this study is for use in schools and includes 58 items. Fifty of these items correspond to self-esteem measurement; the re- 


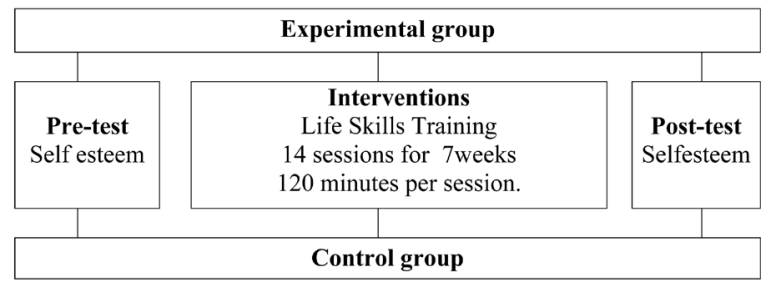

Figure 1. Research design.

maining 8 items were constructed to determine if a participant is taking the measure seriously (the "Lie scale"). It is comprised of 58 unambiguous trait-descriptive sentences to which participants respond by indicating whether the sentences describe them ) either "like me" or "unlike me"). These statements describe feelings, opinions, and reactions typical of the various everyday situations experienced by a college student (Coppersmith, 1975). The SEI is a self-reporting instrument with a testretest reliability of 0.88 and a high degree of internal consistency. The SEI has been widely used in psychological research. The validity and reliability of this instrument are well confirmed. To estimate the reliability coefficients of the inventory version in Iran, a test-retest analysis was done on Iranian high school students. Results showed that the coefficient for the girls was 0.90 and coefficient for the boys was 0.92 . Findings of the study also showed that the validity coefficient of the inventory test was 0.69 for boys' respondents and 0.71 for the girls. Furthermore, the coefficient of Reliability for coppersmiths' SEI was reported as 0.82 (Cronbach alpha), and its internal constancy of the Inventory test was nearly the same to be after six weeks [22]. In addition, Poursharifi (1992) utilized spilt-half reliability method in testing the instrument. It was successfully used on a group of adolescent respondents where a coefficient is 0.83 was observed [23].

\subsection{Leiter International Performance Scale}

The Leiter International Performance Scale was originated by Russell Graydon Leiter who began work on his performance scale in March 1927. The first commercial publication of the Leiter International Performance Scale appeared in 1940. The Leiter International Performance Scale have been very widely used for the intellectual assessment of different populations including deaf, intellectually disabled, autistic, speech and language impaired, non-English speaking, motor-involved, brain injured, and intellectually superior persons. It is considered highly correlated with traditional intelligence tests like the WISC-III Full Scale IQ test. This test was standardized by Tolooie and Mehdi Valojerdi [24].

\section{Procedure}

Life Skills Training: On the basis of the past researches and review of existing programs, a life skills training program was developed. The Life Skills program is a comprehensive behavior change approach that concentrates on the development of the skills needed for life such as self-awareness, communication, decision-making, thinking, managing emotions, relationship skills, daily living skills, survival skills, choices and consequences, interpersonal/social skills, eye contact, tone and volume of speech, conversational skills, and assertiveness. This intervention program worked on promoting child's coping resources, enhancing the social competency and consequently imposing a positive effect on mental health. Training sessions also focused on teaching skill modules using brief didactic instruction, behavioral modeling, role-playing, obtaining direct feedback from therapists, behavioral rehearsal and assertiveness, accepting compliments and implementing the skills.

\section{Results}

Homogeneity of variance studied groups according to age and intelligence were compared using t-test. According to Table 1 using an independent t-test revealed that there is no statistically significant difference between the mean age $(\mathrm{P}=0.94)$ and IQ $(\mathrm{P}=0.30)$ in experimental and control groups.

As it is understood by the Table 2, there is no difference experimental and control groups in pre-test situation but the mean scores for experimental group was increased in Post-test.The score for "self-esteem" of the experimental group increased more than that of the control group. This difference was statistically significant ( $\mathrm{T}$ $=-3.59, \mathrm{DF}=52, \mathrm{P}=037$ ) (Table 2). It can be concluded that life skill training can have a positive impact on effective on increase of self-esteem in hearing impaired students.

\section{Discussion}

For everyone to reach their full potential, a number of critical life skills must be learned. Specific learning opportunities are important for children with special needs. Inclusive education facilitates an environment and opportunities for learning social and academic skills. Schools and teachers could integrate life skills lessons which

Table 1. Compare the experimental and control groups of homogeneous age and intelligence.

\begin{tabular}{ccccccc}
\hline Variable & Group & $\mathrm{N}$ & $\mathrm{M} \pm \mathrm{SD}$ & $\mathrm{DF}$ & $\mathrm{T}$ & Sig. \\
\hline Age & Exp. & 27 & $14.11 \pm 1.94$ & 52 & 0.316 & 0.94 \\
& Con. & 27 & $13.98 \pm 1.99$ & & & \\
IQ & Exp. & 27 & $93.71 \pm 6.99$ & 52 & 0.571 & 0.30 \\
& Con. & 27 & $92.48 \pm 6.80$ & & & \\
\hline
\end{tabular}


Table 2. Comparison of self-esteem between experimental and control groups $(\mathrm{N}=\mathbf{5 4})$.

\begin{tabular}{cccccccc}
\hline Variable & Group & Pre-test & Post-test & Difference & T & DF & P-Value \\
\hline \multirow{3}{*}{ Self-Esteem } & & Mean & Mean & Mean (SD) & & & \\
& Exp. & 18.82 & 29.78 & $10.96(3.94)$ & -3.59 & 52 & $0.037^{*}$ \\
& Con. & 19.21 & 22.04 & $2.83(3.52)$ & & & \\
\hline
\end{tabular}

Exp.: experimental; Con.: control. ${ }^{*} \mathrm{P}<0.05$.

covers social skills training in their curriculum [25]. Selfesteem and Social skill acquisition relates to the theory of emotional intelligence [26]. Emotional intelligence is "the ability to access and interpret a given situation accurately and to manage oneself to relate effectively with others” [27]. Emotional intelligence includes managing emotions or self-control, self-awareness, recognizing emotions in others and handling relationships. If the children tend to be productive, they should manage their feeling and interact with others [28]. Also Bandura's social learning theory can be applied to the social skills development of children. This theory emphasizes the importance of observation, modeling of behaviors, attitudes and emotional reaction of others [25]. In fact, "social learning theory explains human behavior in terms of continuous reciprocal interaction between cognitive, behavioral, and environmental influences" [29]. Halpern [17] argued that curriculums of schools should be based on some balance between social norms and the personal preferences, needs, and choices of the youth. This balance should help the development of both objective and subjective criteria (physical and material well-being, performance of adult roles, and personal fulfillment) and promote life quality. Life skills instruction addresses each of these domains, how and where skills are taught; combined with the goals of inclusive education and community membership. Practitioners must know utilizing the settings and methods are not only effective in terms of instruction, but also enhance community membership and life quality.

The result of this study indicated that life skills training is effective in enhancing the self-esteem of hearing impaired students. This result is consistent with the results of some other researches in this area. A study on negotiation training [30] showed that this kinds of training resulted in stronger changes in overall competence, with changes in the primary domains of interpersonal understanding, interpersonal skills, self-esteem, and the personal meaning of relationships. Some of the social skills that children may develop are: making friends, initiating conversation, joining social groups... which can be taught by modeling, social skills exercises, stories and etc. Development of self-esteem and social skills in hearing impaired child depends on his/her degree of hearing loss, maturity and the age which he/she was diagnosed, the treatment, personality with the experiences they have faced, and the exposure to situation with their peers [5]. Mainstreaming could be difficult for hearing impaired students due to their delay in self-esteem and having problems with social aspect of school. Most children need minimum of instruction to learn these skills but hearing impaired students may need special and directed teaching [31]. Teachers can facilitate the self-esteem development by promoting the interactions through structuring the classroom activities and using appropriate techniques [32].

\section{Limitations}

The sample size could be viewed as a potential limitation. Since there were only 54 students participating in the study (in which only 27 students in experimental group), results of the findings could be difficult to relate to the population of hearing impaired student. Accessibility to one scale for rating the self-esteem could be another limitation of this study. The time constraints of the study could also be an indicator affecting the outcomes. Fourteen session of the intervention occurred over the course of seven weeks and the degree of improvement could not be as expected.

\section{Future Research}

This study could be expanded to include a larger population of students. Further studies resulting from this research could revolve around incorporating any portion of this program for variety of population. Preparation of this program based on the needs of students with disabilities would provide opportunities for their improvements in specific areas. Schools could apply this program to their curriculum too.

\section{REFERENCES}

[1] E. Seifert, S. Brosch, A. G. Dinnesen, A. Keilmann, C. Neuschaefer-Rube, O. Goldschmidt, A. Nickisch, W. Reuter, M. Röhrs and M. Tigges, "Peripheral Hearing Disorders in Childhood. Results of an Evidenced Based Consensus Conference," German Society for and Audiometry and Pediatrics, Vol. 53, No. 4, 2005, pp. 376-382.

[2] M. Huber, "Health-Related Quality of Life of Austrian Children and Adolescents with Cochlear Implants,” In- 
ternational Journal of Pediatric Otorhinolaryngology, Vol. 69, No. 8 2005, pp. 1089-1101.

http://dx.doi.org/10.1016/j.ijporl.2005.02.018

[3] E. Jambor and M. Elliot, "Self-Esteem and Coping Strategies among Deaf Students,” Journal of Deaf Studies and Deaf Education, Vol. 10, No. 1, 2005, pp. 63-81. http://dx.doi.org/10.1093/deafed/eni004

[4] A. Keilmann, A. Limberger and W. Man, "Psychological and Physical Well-Being in Hearing Impaired Children," International Journal of Pediatric Otorhinolaryngology, Vol. 71, No. 11, 2007, pp. 1747-1752. http://dx.doi.org/10.1016/j.ijporl.2007.07.013

[5] R. Patton, "Social Skills Issues of Mainstreaming Hearing Impaired Children," Washington University School of Medicine, St. Louis, 2004.

[6] S. M. Sheridan and D. Walker, "Social Skills in Context: Considerations for Assessment, Intervention, and Generalization,” In: C. R. Reynolds and T. B. Gutkin, Eds., The Handbook of School Psychology, 3rd Edition, Wiley, New York, 1999, pp. 686-708.

[7] S. Oden and S. Asher, "Coaching Children in Social Skills for Friendship Making," Child Development, Vol. 48, No. 2 1997, pp. 495-506. http://dx.doi.org/10.2307/1128645

[8] S. Antia and K. Kreimeyer, "Social Intervention and Acceptance of Deaf or Hard of Hearing Children and Their Peers: A Comparison of Social Skills and FamiliarityBased Intervention,” Volta Review, Vol. 98, No. 4, 1996, pp. 157-180.

[9] B. Esposito and M. Koorland, "Play Behavior of Hearing Impaired Children: Integrated and Segregated Settings," Exceptional Children, Vol. 55, No. 5, 1989, pp. 412-419.

[10] A. A. Samarei and A. Lalei Faz, "Efficacy of Teaching Life Skills on Family Stress and Social Acceptance,” The Quarterly Journal of Fundamentals of Mental Health, Vol. 7, 2005, pp. 47-55.

[11] J. Maghsoudi, N. Hashemisabour, M. Yazdani and T. Mehrabi, "The Effect of Acquiring Life Skills through Humor on Social Adjustment Rate of the Female Students," Iranian Journal of Nursing and Midwifery Research, Vol. 15, No. 4, 2010, pp. 195-201.

[12] WHO, "Life Skill Education for Children and Adolescents in School," World Health Organization, Geneva 1997.

[13] H. Kingsnorth, S. Healy and C. Macarthur, "Preparing for Adulthood: A Systematic Review of Life Skill Programs for Youth with Physical Disabilities," Journal of Adolescent Health, Vol. 41, No. , 2007, pp. 323-332.

[14] M. Ahmadian and L. Fata, "P02-161 the Effect of Life Skills Education on Mild Intellectual and Developmental Disability,” European Psychiatry, Vol. 24, Supplement 1, 2009, p. S851. http://dx.doi.org/10.1016/S0924-9338(09)71084-3

[15] F. Cunha, J. Heckman, L. Lochner and D. Masterov, "Chapter 12 Interpreting the Evidence on Life Cycle Skill Formation," Handbook of the Economics of Education, Vol. 1, 2006, pp. 697-812. http://dx.doi.org/10.1016/S1574-0692(06)01012-9
[16] M. E. Cronin, "Life Skills Curricula for Students with Learning Disabilities: A Review of the Literature,” Journal of Learning Disabilities, Vol. 29, No. 1, 1996, pp. 5368. http://dx.doi.org/10.1177/002221949602900108

[17] A. S. Halpern, "The Transition of Youth with disabilities to Adult Life: A Position Statement of the Division on Career Development and Transition," Career Development for Exceptional Individuals, Vol. 17, No. 2, 1994, pp. 115-124.

[18] M. Alwell and B. Cobb, "Teaching Functional Life Skills to Youth with Disabilities,” Executive Summary, 2006. www.nsttac.org

[19] D. Warnes, M. Sheridan, G. Geske and W. William, “A Contextual Approach to the Assessment of Social Skills: Identifying Meaningful Behaviors for Social Competence,” Psychology in the Schools, Vol. 42, No. 2, 2005, pp. 173187. http://dx.doi.org/10.1002/pits.20052

[20] T. Nunes, U. Pretzlik and J. Olsson, "Deaf Children's Social Relationships in Mainstream Schools," Journal of Deaf Education International, Vol. 3, No. 3, 2001, pp. 123-136.

[21] A. Huether, "Impact of Integrated and Non-Integrated Schooling of the Hearing Impaired in Special Schools. Results of a Comparative Survey Students with Special Emphasis on Results at Regular Schools," Hearing Education, Vol. 55, No. 1, 2001, pp. 28-133.

[22] H. Shokrkon and A. Nisi, "The Effect of Self-Esteem on Function of Students,” Journal of Psychology, Vol. 1, No. 3, 1995, pp. 25-31.

[23] M. Roghanchi, A. Mohamad, K. Momeni and M. Golmohamadian, "The Effect of Integrating Rational Emotive Behavior Therapy and Art Therapy on Self-Esteem and Resilience,” The Arts in Psychotherapy, Vol. 40, No. 2, 2013, pp. 179-184.

[24] A. Tolooie and M. Mehdi Valojerdi, "Standrized Leiter-R in Persian,” Special Education Organization, 2007.

[25] M. Quigley, “The Effects of Life Skills Instruction on the Personal-Social Skills Scores of Rural High School Students with Mental Retardation,” A Dissertation Presented to the Faculty of the School of Education, Liberty University, Lynchburg, 2007.

[26] D. Goleman, "Working with Emotional Intelligence," Bantam Books, New York, 1998.

[27] S. Kolb and C. Hanley-Maxwell, "Critical Social Skills for Adolescents with High Incidence Disabilities: Parental Perspectives," Council for Exceptional Children, Vol. 69, No. 2, 2003, pp. 163-179.

[28] Menta, "Clinical Services Model," Special Education Services, 2006. www.mentagroup.com

[29] G. Kearsley, "Social Learning Theory (A. Bandura). Exploration in Learning \& Instruction: The Theory into Practice Database,” 2006. http://tip.psychology.org/bandura.html

[30] M. J. Nakkula and C. E. Nikitopoulos, "Negotiation Training and Interpersonal Development: Exploratory Study of Early Adolescents in Argentina,” Adolescence, Vol. 36, No. 141, 2001, pp. 1-20. 
[31] D. Mannix, "Social Skills Activities for Special Children," Center for Applied Research in Education, New York, 1993.
[32] D. Todd and M. Mclaughlin, "Social Skills Groups for Special Needs Students,” 2003. http://www.ispaweb.org/ 